\title{
Fatigue as the Presenting Symptom of Multiple Endocrine Neoplasia of Type 2A
}

\author{
NURDAN GUL , AYSE KUBAT UZUM , GULSAH YENIDUNYA YALIN, FERIHAN ARAL, REFIK TANAKOL
}

ISTANBUL UNIVERSITY, ISTANBUL FACULTY OF MEDICINE, DIVISION OF ENDOCRINOLOGY AND METABOLISM

Introduction: Clinical spectrum of pheochromocytoma syndromes are very heterogeneous. Sometimes life threatening hypertensive attacks may be the presenting symptom or the clinical picture may be subtle that a nonspecific symptom like fatigue can lead to diagnosis. We herein present two pheochromocytoma cases with distinct clinical features.

Case 1: 20-year-old female patient admitted to emergency department with blurred vision and headache. She experienced headache for three years and once she had a seizure and lost consciousness for four hours. During the course blurred vision recurred and examination revealed papilledema and retinal haemorrhage. Thorax CT-angiography performed for a presumptive diagnosis of Takayasu's arteritis revealed a 3.5-cm right adrenal mass, and she was referred to our endocrinology clinic. She was hypertensive, and urinary catecholamines were very high (table 1). She had no family history of pheochromocytoma and work-up for hereditary syndromes were negative. After preoperative preparation, she was successfully operated. Histopathological examination was compatible with pheochromocytoma.
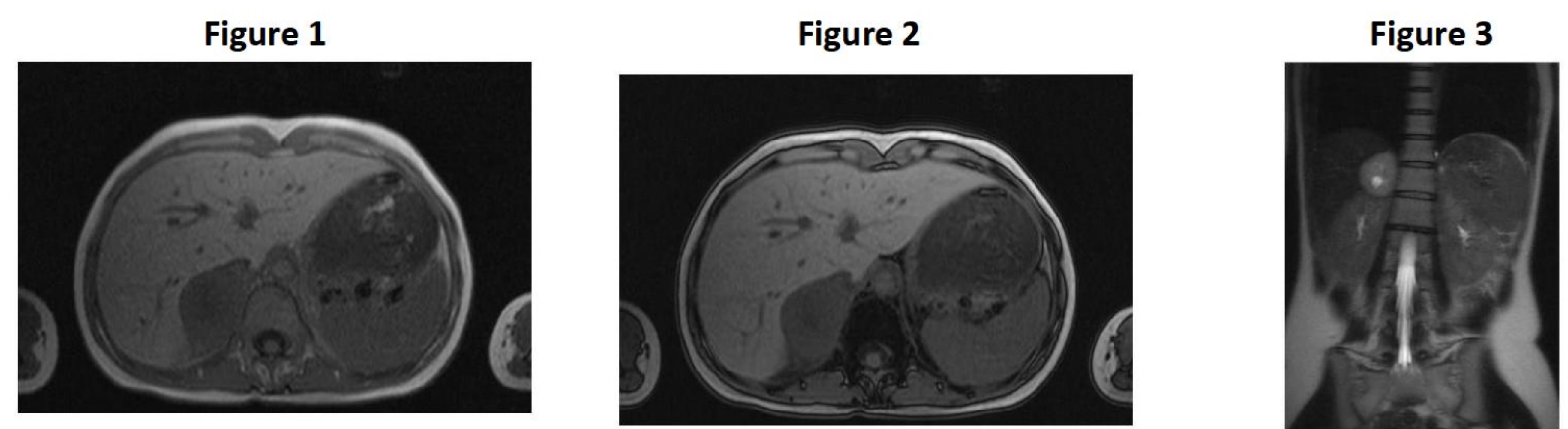

Figure 1-3: MR images of Case 1 showing 44×33×45 mm right adrenal mass lesion with cystic component.

Case-2: 30-year-old male patient was evaluated by his family physician because of fatigue. He was anxious as his father died of metastatic brain cancer. His laboratory evaluation revealed slightly elevated carcinoembryonic antigen. Endoscopic examination of the gastrointestinal tract was normal, but abdominal ultrasound showed $6-\mathrm{cm}$ pancreatic and adrenal mass lesions, and MRI showed bilateral adrenal mass. His blood pressure was $130 / 90 \mathrm{mmHg}$. He did not have a history of hypertension, but he described occasional headaches. His urinary catecholamines were very high (table 1). Calcitonin level was $34.8 \mathrm{ng} / \mathrm{ml}$. He underwent bilateral adrenalectomy, and pathologic examination confirmed pheochromocytoma. RET protooncogen was positive, and total thyroidectomy revealed multifocal medullary thyroid cancer.

Figure 4

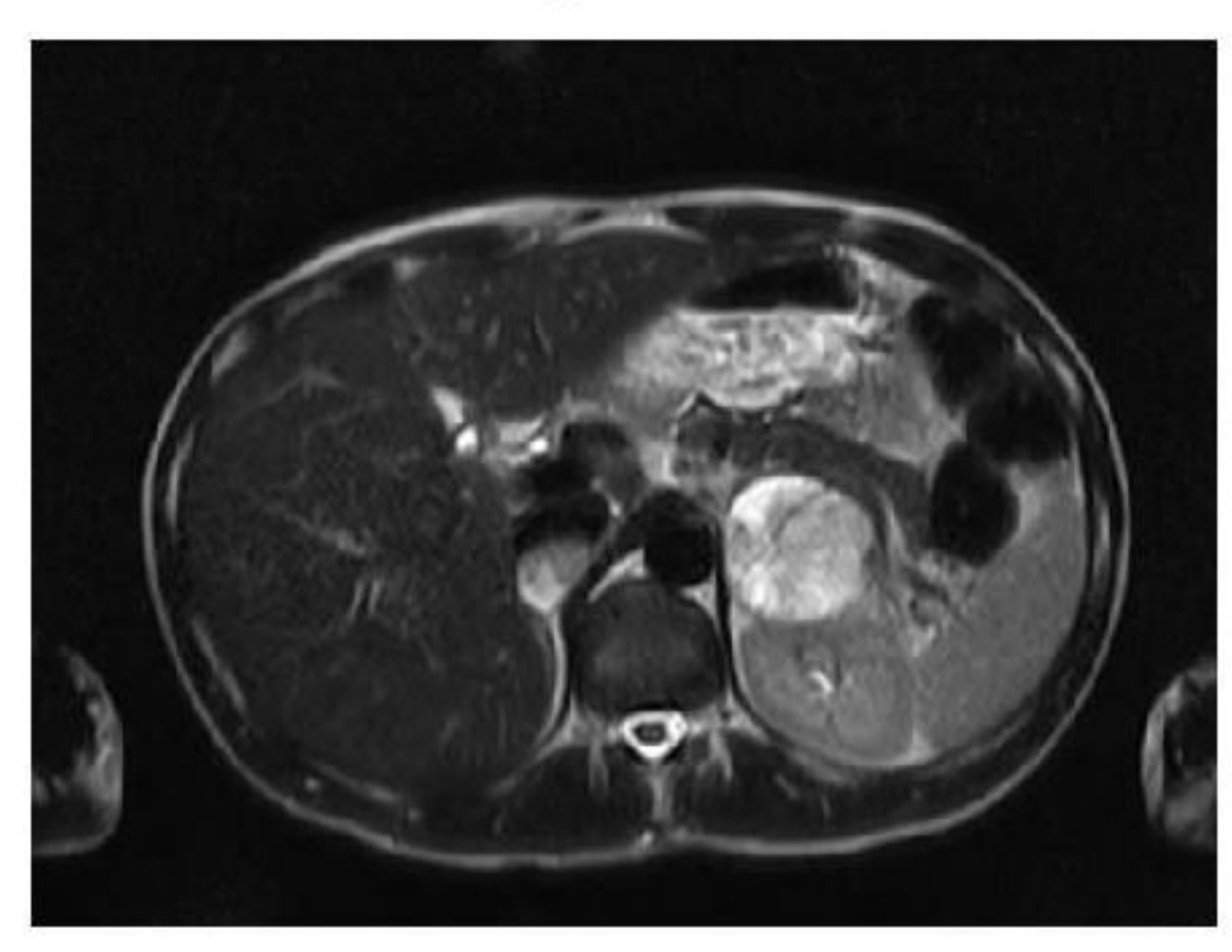

Figure 5

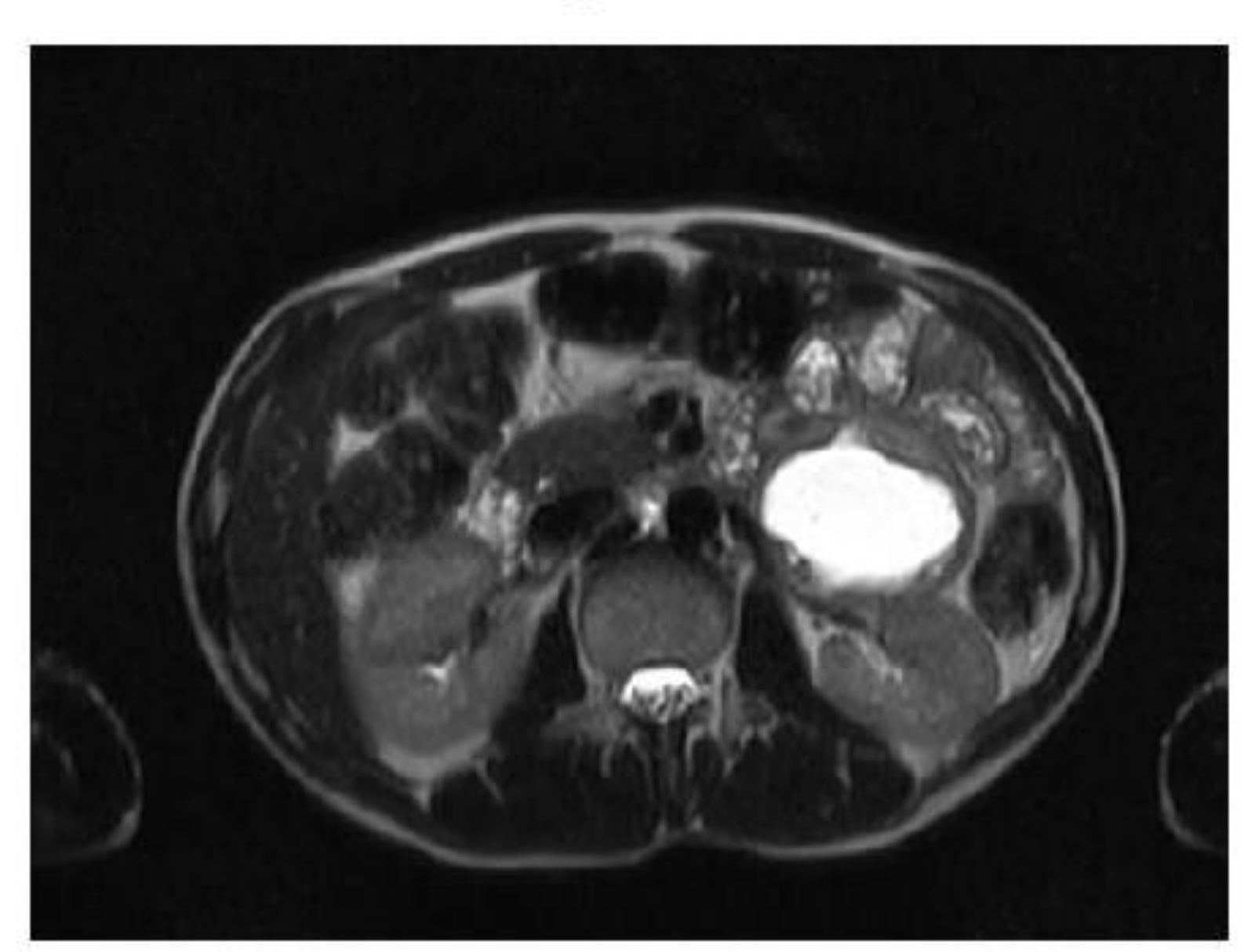

Figure 6

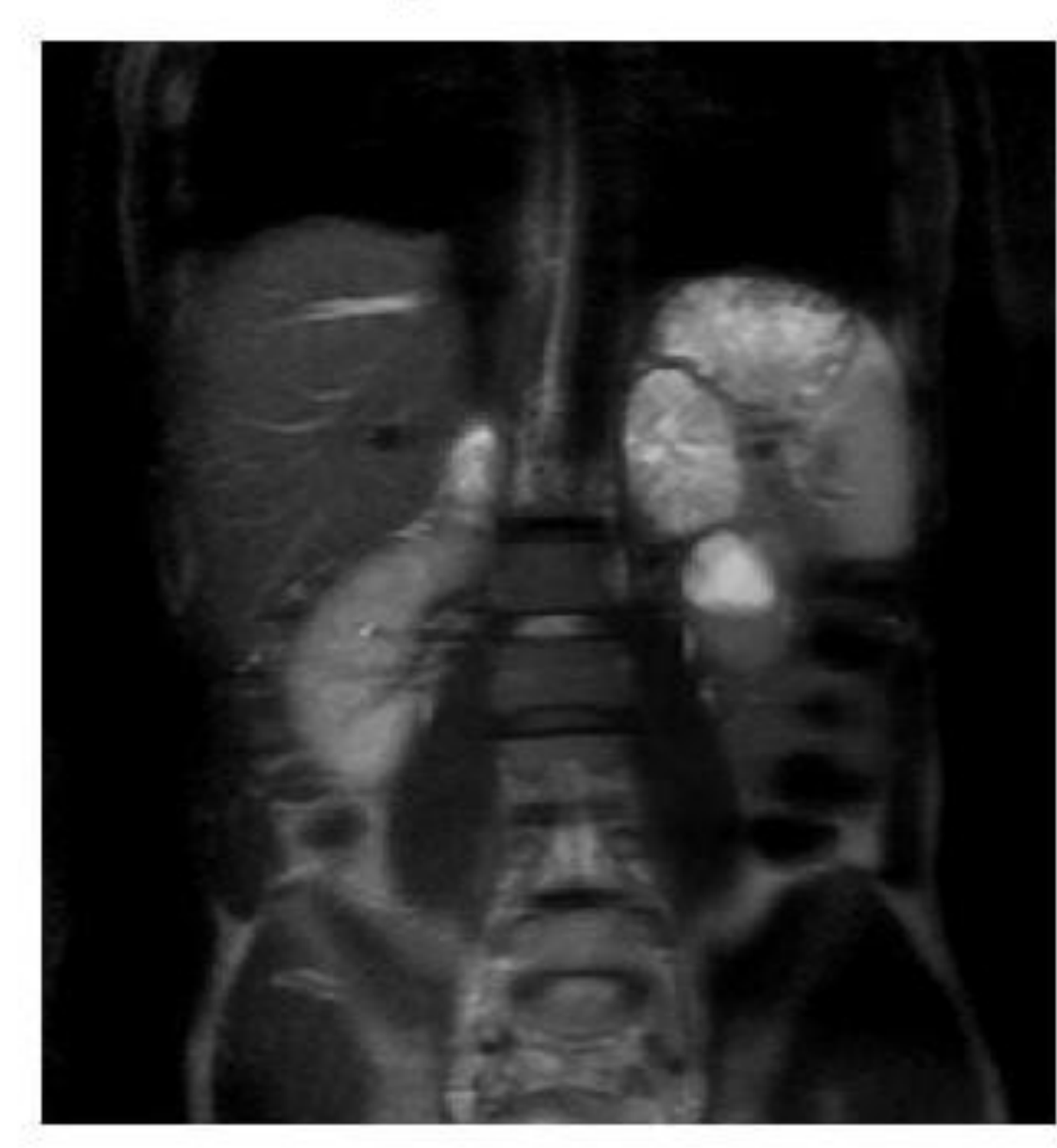

Figure 4-6: MR images of Case 2 showing bilateral adrenal mass lesions. On T2-weighted images lesions are hyperintense and inhomogeneous.

\begin{tabular}{|c|c|c|}
\hline $\begin{array}{l}\text { Urinary Cathecolamines } \\
\text { ( } \mu \mathrm{g} / \text { day) }\end{array}$ & Case 1 & Case 2 \\
\hline Dopamine (N: 190-450) & 310.64 & 338 \\
\hline Metanephrines (N: 52-341) & 128.26 & 11477 \\
\hline Noradrenaline (N:23-105) & 4248.75 & 1556 \\
\hline Normetanephrines (N: 88-444) & 18077.40 & 8062 \\
\hline Adrenaline (N: 4-20) & 20.89 & 915 \\
\hline
\end{tabular}

Table 1

Conclusion: Even fatigue can be the presenting symptom of MEN2A, and clinical picture does not correlate with the extent of disease in pheochromocytoma syndromes. 